\title{
FATORES QUE DIFICULTAM O ACESSO DAS MULHERES AO PODER LEGISLATIVO NO BRASIL
}

\author{
Maria Inês do Rosário Brito ${ }^{1}$ \\ Jaqueline José Silva Oliveira ${ }^{2}$ \\ Roseane Cavalcante de Souza ${ }^{3}$
}

Resumo: Este artigo objetiva analisar a dificuldade do acesso da mulher aos espaços de poder. Destaca como entrave da conquista deste gênero chegar ao Poder Legislativo o ranço machista da tradicional política brasileira. Tal entrave é legitimado, ao longo desta política, pelo comportamento social, o qual resulta na ineficácia da Lei das Cotas de gênero

\section{Introdução}

A inserção da mulher no Poder Legislativo, ainda, é considerado um processo difícil, mesmo com a criação da Lei de Cotas de Gênero (Lei n.9.504/97).

Os fatores que dificultam o acesso das mulheres em tal Poder, no Brasil, envolvem questões históricas e culturais, falta de espaço na militância partidária, a resistente dominação masculina, o descaso dos candidatos à

\footnotetext{
${ }^{1}$ Possui graduação em Direito pela Faculdade de Ciências e Educação de Rubiataba. Viceprefeita de Ceres, eleita, em 2012, prefeita do citado Município.

${ }^{2}$ Jaqueline José Silva Oliveira: Mestre em Direito, Relações internacionais e Desenvolvimento (PUC-GO) aluna especial no doutorado em Direito Ambiental Internacional (Universidade Católica de Santos), graduada em Direito e Letras habililtação Português/Inglês. Professora da Facer- Faculdades. E-mails: jaquelineprofessora@hotmail.com

3 Professora Mestre em Direito Agrário (UFG), coordenadora da implantação do projeto pedagógico do curso de Direito em Rubiataba, professora de Direito Civil e Agrário.
} 
eleição referente à mulher candidata, o poder financeiro na eleição versus a renda feminina e a estrutura institucional patriarcal.

Nesse sentido, o tema enseja o questionamento se tal lei trouxe mudanças efetivas para a erradicação dos fatores que impedem o acesso da mulher ao poder em questão.

O estudo foi realizado com aplicação de pesquisa bibliográfica por meio de consultas em livros, revistas e websites.

Utilizou-se o método histórico para demonstrar o patriarcalismo no transcorrer da história política do Brasil. Ainda, o método estatístico em relação aos dados que refletem o impacto das leis que incluem socialmente as mulheres, no contexto político no Brasil, os método-hipotético dedutivo.

O desenvolvimento deste trabalho está ancorado em duas partes: a primeira trata dos fatores históricos e culturais em relação à participação da mulher na política brasileira. A segunda demonstra os dados que refletem 0 impacto das leis que incluem socialmente as mulheres. A terceira aborda os pontos positivos Lei n.9.504/97 e sua Ineficácia. Posteriormente, são apresentadas as considerações finais.

\section{Fatores Históricos/Culturais}

A dificuldade do acesso da mulher aos espaços de poder ocorre por vários fatores, entre eles, destacam-se a tradição política no Brasil (fatores históricos culturais) e o comportamento social o qual influencia diretamente o indivíduo, fazendo-o considerar que a conquista do poder político é prerrogativa do homem, pois as mulheres têm a responsabilidade de zelar dos filhos e do lar. Neste sentido, relata Choinaski, (1998, p. 239): 


\begin{abstract}
Nas campanhas eleitorais as mulheres aceitam o desafio de serem candidatas, mas o problema é o tipo de campanha e o tratamento dado às disputas. Muitas mulheres nunca tiveram renda e não têm como entrar na disputa; muitas têm certo medo, pois os homens estão acostumados a falar em público e com isso têm um poder a mais, aumentando as dificuldades das candidatas. Pela nossa formação cultural, acabamos tendo medo. Fomos condicionadas a isso e não é fácil lidar com essa insegurança. Ou seja, as condições são desiguais entre homens e mulheres. O partido não coloca como prioridade a eleição de mulheres. (CHOINASKI, 1998, p.239)
\end{abstract}

Outro aspecto desafiador é a falta de espaço na militância dentro dos partidos políticos, em razão da maioria das direções partidárias, em regra, ser composta por homens, os quais se acostumaram com o apoio da mulher ${ }^{4} \mathrm{e}$ não conseguem, ainda, abrir espaço e criar as condições para a militância feminina. A pesquisadora Choinaski $(1998,239)$ defende:

(...) Em primeiro lugar, qual a condição que o partido deu para a sua participação efetiva? Quem tem criança não pode participar de reuniões porque não tem onde deixar o filho. As reuniões não foram pensadas a partir das mulheres, mas sempre a partir dos homens. A começar pela questão do horário, pois os homens não se preocupam se temos condições de participar ou não. (CHOINASKI, 1998, p.239)

A sociedade está acostumada a impor as atividades domésticas à mulher, e elas assumiram, e se condicionaram a este papel. Isso é um aspecto que dificulta a militância partidária. Luana Simões ${ }^{5}$ continua a reflexão acerca desse obstáculo colocado pelos partidos políticos.

\footnotetext{
5 - Luana Simões Pinheiro, economista do Instituto de Pesquisa Econômica Aplicada (Ipea), atua como técnica de Planejamento e Pesquisa. Além disso, é membro do Centro de Direitos Humanos da Universidade de Essex, nos Estados Unidos, e mestranda em sociologia pela UnB. Entre os seus diversos trabalhos, ela tem se destacado na elaboração e publicação de estudos na área social, especialmente sobre as questões de gênero e raça. Colaborou no desenho e no desenvolvimento de importantes estratégias do governo federal para o combate às desigualdades de gênero e raça, como o Plano Nacional de Políticas para as Mulheres, lançado em 2004.
} 
As resistências e preconceitos presentes nas organizações partidárias, ao acesso seletivo aos recursos econômicos e sociais, aos papéis de gênero e à socialização diferenciada que, por meio da formação educacional e da cultura dominante, não favorece a preparação da mulher para a disputa política e para o poder. (PINHEIRO, 2007, p. 76)

Com as mudanças na legislação eleitoral, cotas, obrigação de usar no mínimo $10 \%$ dos recursos partidários em atividades voltadas a mulher, o comportamento social busca se adequar, porém, será necessário um espaço de tempo em que se mude esse jeito de pensar e que a mulher não seja apenas apoio. Mas, que possua autonomia, opinião própria, a qual nem sempre agrada aos homens que antes a dominavam. Contudo, demonstra sua capacidade de exercer a sua cidadania. A autora continua:

\begin{abstract}
O relacionamento das mulheres com os partidos, tradicionalmente, tem sido mais sazonal do que contínuo, e envolve participação nas campanhas de outros candidatos, ajuda na organização de eventos, mas sempre com muito poucas mulheres como candidatas lançadas pelo partido. Em geral, os motivos alegados para explicar o irrisório incentivo e o pouco espaço das mulheres nas estruturas partidárias referem-se ao fato de que as mulheres serem recém-chegadas na arena política formal, não terem tradição como grupo social nem contarem, geralmente, com a força de organizações econômicas e profissionais. Cria-se, assim, um círculo vicioso, pois às mulheres não se dá espaço porque não têm capital político e, sem esse espaço, elas não conseguirão o capital necessário para se fazerem notadas e reconhecidas nos partidos e, conseqüentemente, para garantirem presença nos canais formais de representação. (PINHEIRO, 2007, p. 83)
\end{abstract}

Depois de tanta exclusão, ainda querem remeter as mulheres a culpa da sua não participação, de quem será a responsabilidade desse círculo vicioso? De quem é o dever de reverter esse quadro? A sociedade tem que reagir para modificar essa realidade social, permitindo relações mais democráticas a todos os excluídos dos espaços de poder, entre eles, a mulher. Observa-se aqui que a falta de exercício político é fator determinante para o pouco desempenho feminino, e a recíproca é valida fazendo do homem o principal protagonista na arena política brasileira. 
As questões pessoais e familiares também têm grande impacto nesse contexto, em que as esposas são companheiras e nem sempre conseguem a compreensão dos maridos quando elas estão na função pública. Miguel e Grossi, citado por Pinheiro (2007, p.79) expressa essa dura realidade:

(...), Miguel e Grossi enfatizam também as dificuldades originadas do exercício solidário do poder. Para elas, no caso dos políticos homens, o peso emocional do exercício do poder é compartilhado, na maioria dos casos, com as esposas que ocupam o cargo de primeira-dama; são companheiras obrigatórias para as atividades políticas do marido, o que, muitas vezes, acaba sendo a via de acesso ao mundo político para essa parcela das mulheres. Já para as mulheres candidatas e eleitas a realidade é de uma atuação política mais solitária, uma vez que é muito comum o término de casamentos quando se dedicam à vida política. (PINHEIRO, 2007, p.79)

Essa dicotomia tem sua base nos aspectos educacionais também, pois as mulheres não são educadas para ocupar espaços de poder, e, sim para se manter em espaços privados. Pinheiro afirma:

O acúmulo de capital social e político são difíceis para qualquer indivíduo, e ainda mais para as mulheres. Por serem socializadas de maneira diferenciada e sem orientação para a participação política, acabam convertendo seu conjunto de habilidades em um "capital emocional", entendido como um conjunto de relações, conhecimento, contatos e habilidades aplicáveis muito mais à dominação interna à família ou às relações de parentesco e amizade, e pouco eficaz no campo profissional e no político. (PINHEIRO, 2007 p.81, 82)

O capital emocional é formado a partir da família que absorve e reproduz valores sociais impostos para manter o modelo patriarcal, daí a dificuldade de romper com essa cultura, pois as vítimas(mulheres) não têm estruturas para quebrar esses paradigmas, por exemplo, a pesquisa, realizada pela Fundação 
Perseu Abramo (FPA ${ }^{6}$, analisada e comentada por 10 pesquisadoras na Obra "A mulher brasileira nos espaços públicos e privados", publicada em 2004 pela Editora da mesma fundação.

\section{Dados que Refletem o Impacto das Leis que Incluem Socialmente as Mulheres}

$\mathrm{Na}$ citada pesquisa foi, primeiramente, respondida a seguinte questão: Qual dessas frases representa melhor a sua opinião sobre mulheres governarem? O resultado confirma o preconceito impregnado na própria mulher pela sua convivência social, pois somente $59 \%$ delas responderam que elas estão preparadas para governar o País, o Estado e o Município.

As demais se dividem $11 \%$ somente estado e município e não o País; $8 \%$ somente as cidades; e $4 \%$ não sabem. Restando ainda $18 \%$ que acham que elas não estão preparadas para governar. Conforme tabela a seguir:

Tabela 6 - Opinião sobre o preparo das mulheres para governar (estimulada, em \%)

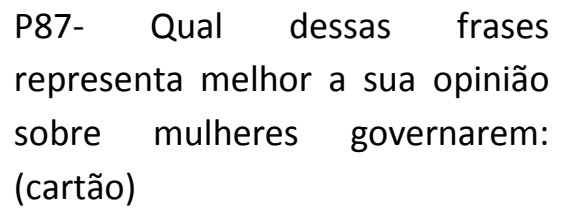

6- A Fundação Perseu Abramo foi instituída pelo Partido dos Trabalhadores no dia 5 de maio de 1996. Com o objetivo de construir um espaço, fora das instâncias partidárias, para desenvolvimento de atividades como as de reflexão política e ideológica, de promoção de debates, estudos e pesquisas, com a abrangência e a pluralidade de opiniões. 


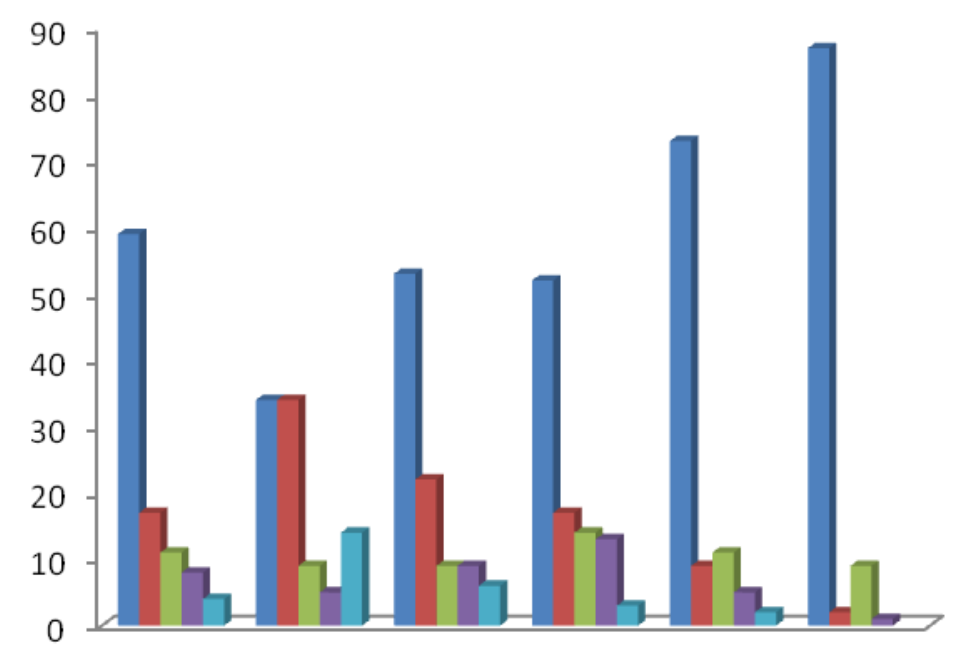

- As mulheres estão preparadas para governar o país, o estado e a cidade

E As mulheres não estão preparadas para governar

As mulheres estão preparadas para governar o estado e a cidade, mas não o país

- As mulheres estão preparadas para governar a cidade, mas não o estado nem o país

(RAGO, et al, 2004, p.241)

Outro dado da pesquisa que confirma o efeito desse preconceito enraizado no comportamento é retratado na tabela 7 (Importância da política, segundo escolaridade), onde somente $38 \%$ do total das pesquisadas considera política como sendo coisa muito importante e $23 \%$ nada importante. O que reflete a pouca presença delas no meio político.

Tabela 7 - Importância da política, segundo escolaridade.

(estimulada, em \%) 


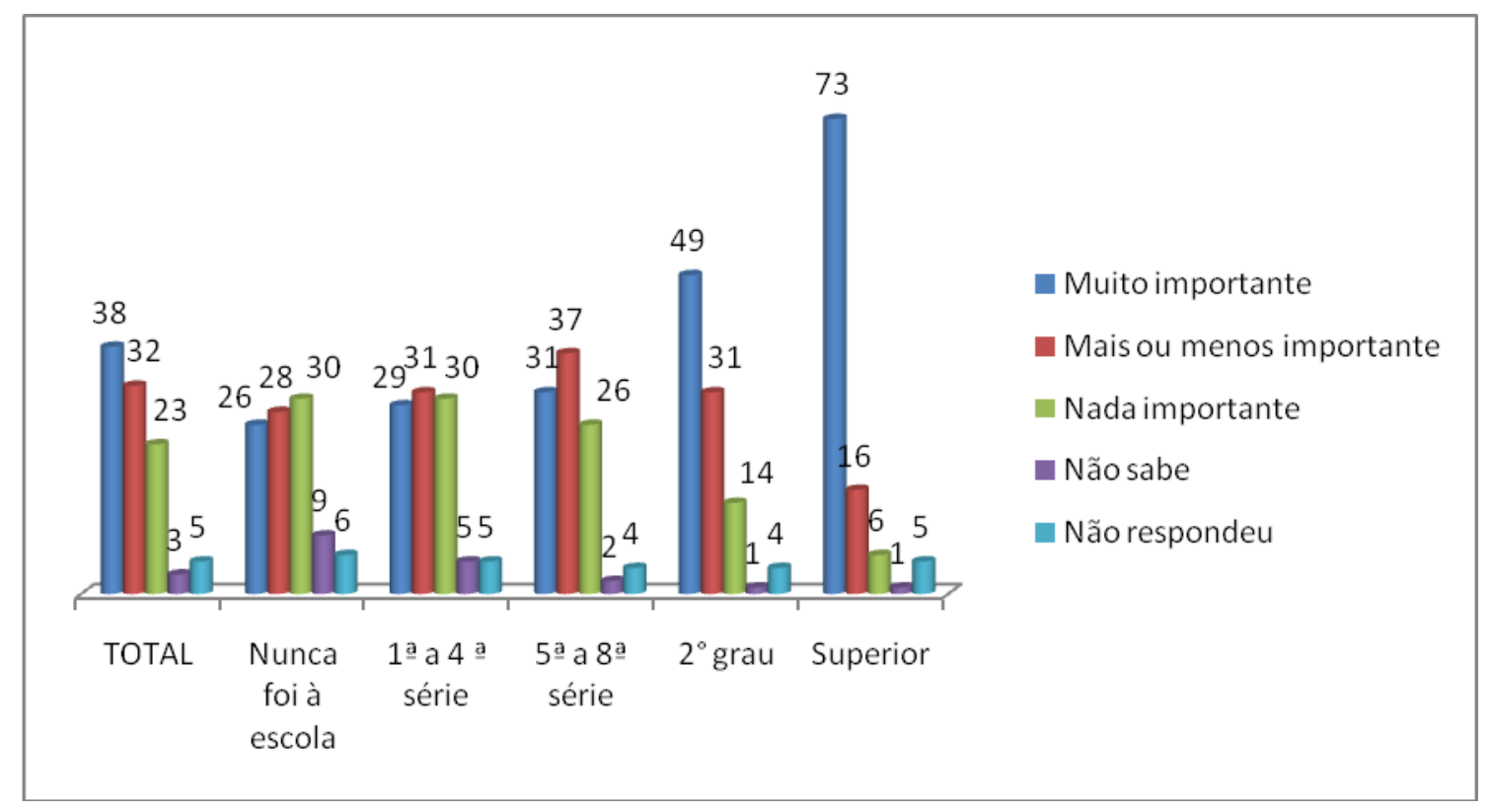

(RAGO,et al 2004, p.238)

\subsection{O Impacto da Dominação Masculina}

Bourdieu apud Pinheiro (2007, p.39) se utiliza de uma das teorias bourdieuna que defende a dominação como fenômeno cristalizado nas estruturas, em que o dominado aceita a condição por entender como sendo natural:

O fenômeno da dominação está impregnado nas estruturas de pensamento de dominados e dominantes e se expressa no próprio corpo por meio da manifestação de seus habitus, sendo este a "força dormente de onde a violência simbólica extrai à sua eficácia". (BORDIEU,In PINHEIRO, 2007, p.39)

A formação adquirida pelas mulheres ao longo de sua história vem consolidando, cada vez mais, essa idéia, de que cabe a ela ser submissa ao macho, seja na família, na escola, no trabalho e na igreja. Não seria diferente na vida pública. 
diferenciada e dos valores, que dizem respeito ao processo de construção de papéis sociais diferenciados para homens e mulheres com base em uma concepção de gênero. Essa diferenciação se inicia no ambiente familiar, mas tem continuidade em outras instituições sociais que acabam por difundir e reforçar a separação de papéis entre homens e mulheres, reproduzindo uma concepção tradicional do que é ser homem e do que é ser mulher. Desse modo, um conjunto de estereótipos que tem sido constantemente combatidos pelos movimentos feministas e de mulheres perpetua-se para além da escola e alcança o momento de decisão profissional, no qual as mulheres acabam deslocando-se para espaços ditos "femininos"'e "tradicionais" (serviço doméstico, serviço social, pedagogia), enquanto os homens concentram-se nas atividades "modernas", tais como aquelas das áreas de ciências exatas e informática. (PINHEIRO, 2007, p.77)

A idéia de que a política é coisa de homem vem do fato de que esse não é considerado um espaço feminino, daí porque em geral, muitas mulheres têm dificuldade de se dispor para a candidatura, muitos esposos têm problemas para estimularem suas companheiras e muitos cidadãos(as) não votam em mulheres. Constata-se também que algumas chegaram aos mandatos pelo sobrenome do marido.

As mulheres hoje ocupam importantes espaços no mundo do trabalho, apesar das desigualdades salariais e outros tipos de discriminação, mas, na sua maioria, continuam responsáveis pelas tarefas domésticas e pelos cuidados dos filhos. Romperam barreiras importantes, mas ainda são poucas as que conseguem enfrentar 0 espaço da política, e o fazem, em geral, com grandes sacrifícios: não tem intimidade com este espaço tradicionalmente masculino. (BORBA, 1998, p.168)

Como foram educadas para o cuidado, a agressividade da política é algo que assusta e dificulta sua militância, conforme depoimento de uma vereadora do Município de Goiânia em 1996 relatado por Borba (1998, p.166)

[...] Diferente do que a maioria desejaria, a disputa embrutece as relações e transforma os companheiros em declarados concorrentes [...] Integrar completamente uma campanha e, ao mesmo tempo, discordar de sua cultura e viabilizar outro procedimento, em pouquíssimo tempo, parece inócuo. (MARINA SANT'ANNA, In BORBA, 1998, p.166) 
Além de todas as dificuldades apresentadas anteriormente, faz-se necessário destacar a questão do poder financeiro na eleição e a renda feminina. O custo da campanha é também considerado significativo na exclusão das mulheres de possíveis candidaturas, devido à pouca renda da maioria das candidatas.

Conforme tabela 8 (Renda Familiar Mensal, Segundo Escolaridade) onde a renda delas são ainda pequenas, pois $41 \%$ recebem até 2 salários, $34 \%$ de 2 a 5 e somente $6 \%$ recebem mais de 10 salários e $2 \%$ acima de 20 salários. Portanto, torna-se necessária a reforma política, pois o financiamento público seria uma alternativa para reforçar a ampliação do número de mulheres na vida pública.

Tabela 8 - Renda Familiar Mensal, Segundo Escolaridade (estimulada e única, em \%)

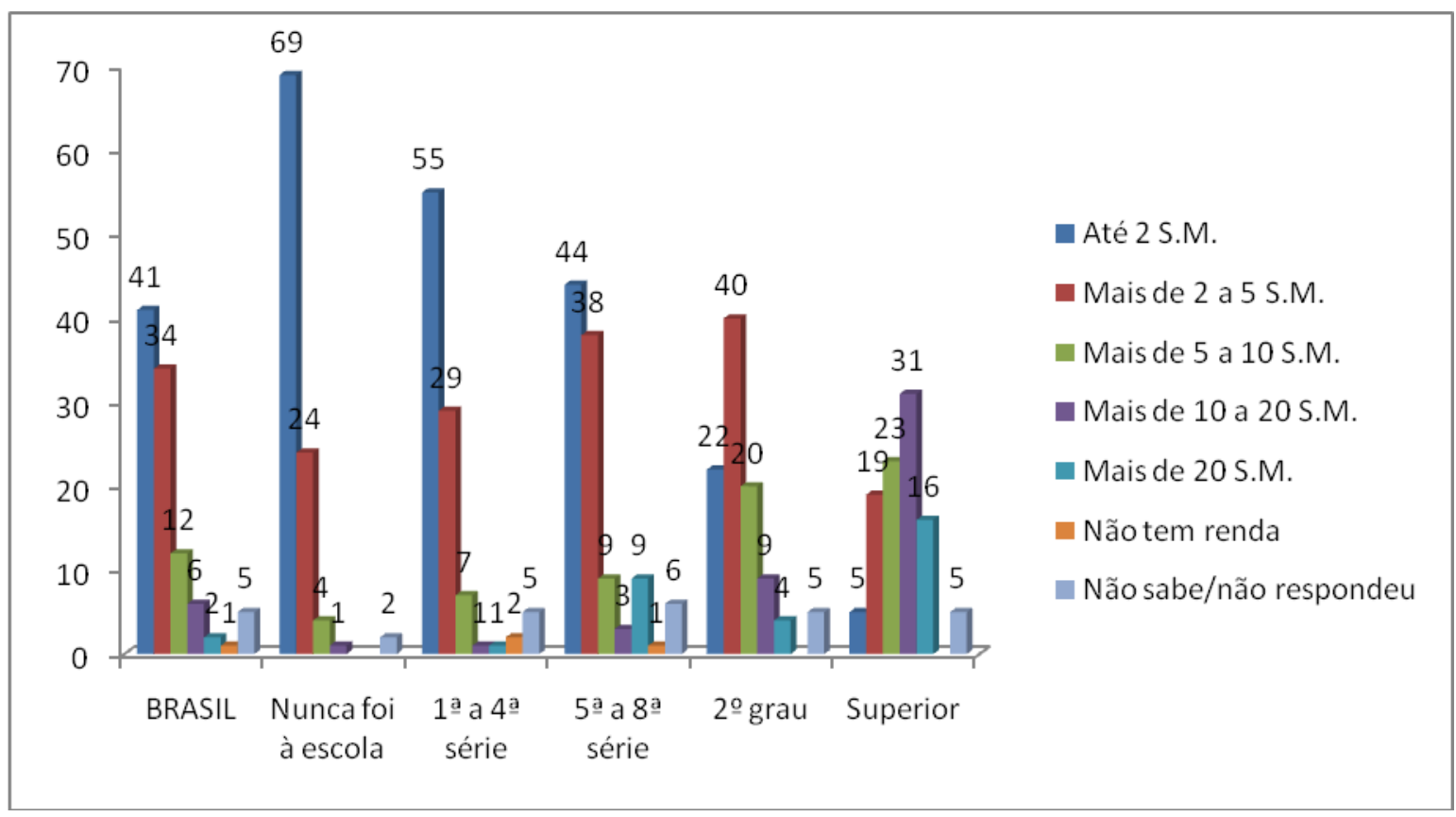

(PINHEIRO, 2007, p.196) 


\subsection{Estrutura Institucional Patriarcal}

Por último, vale destacar o desequilíbrio na estrutura institucional brasileira, que foi gradativamente sendo montada para o homem a partir da linguagem utilizada.

Em relação às estruturas arquitetônicas dos prédios e a equipe de assessoria em todos os poderes Executivo, Legislativo ou Judiciário, nota-se a existência de uma estrutura pronta para receber os homens e uma dificuldade para ser adequada quando chega alguma mulher, o que se torna também mais uma barreira a ser enfrentada por elas.

Toda esta dificuldade começa com a educação diferenciada que as crianças recebem em função de seu sexo: meninos são educados para o espaço público, para a disputa, para a competição, e meninas são treinadas desde cedo para as tarefas domésticas. (BORBA, 1998, p.168)

Portanto, as estatísticas demandam modificar o comportamento social, o que passa necessariamente pela educação. Romper com essas barreiras e tantos preconceitos são condições para garantir a oportunidade de uma nova formação pessoal para homens e mulheres. Ficando, assim, claro que só a modificação da lei eleitoral não garante o aumento do número de mulheres nos espaços de poder, resta, ainda, uma longa caminhada a ser percorrida por quem acredita e trabalha na construção de uma verdadeira Democracia no Brasil.

A comprovação de que somente a mudança da lei não modifica o resultado eleitoral é percebida nos dados demonstrado na tabela 9 (Evolução do número de candidatas e de mulheres eleitas para a Câmara Federal no período pré-cota e pós-cota (1994 à 2010) onde confirma-se que a partir da 
existência da Lei n. 9.504, de 30 de setembro de 1997 o número de candidatas teve um mento de 185 em 1994 para 2.201 candidatas para a Câmara Federal em 2010. Tal aumento, referente o número de candidatos em relação ao mesmo período, é pouco.

Observa-se quanto ao percentual de mulheres eleitas, o aumento não existiu, sendo que em 1994, ${ }^{7} 38$ deputadas federais ocuparam a cadeira, fazendo um percentual de $7,4 \%$ das candidatas. Enquanto em $1998^{8}, 2002$, 2006 e 2010, elegeram-se 29, 42, 45 e 42, respectivamente, existindo um leve aumento numérico, em percentual a partir de 2002 e se estabilizou por quase uma década.

Todavia, destaca-se, ainda, que o percentual de eleitas com relação ao número de candidatas reduziu drasticamente, saindo de 20,54\% em 1994; 8,21\% em 1998; 8,57 em 2002; 7,14 em 2006 chegando a 1.90\% em 2010. Em contradição aos números de candidatas que disputaram as eleições em 1994, 1998, 2002, 2006 e 2010, sendo 185, 353, 439, 737 e 2.201 mulheres que se registraram na mesma ordem dos anos citados anteriormente. Confirmando-se, assim, que houve um aumento real no registro das candidaturas femininas no País.

Tabela 9 - Evolução do número de candidatas e de mulheres eleitas para a Câmara Federal no período pré-cota e pós-cota (1994 à 2010)

\begin{tabular}{|l|l|l|l|l|l|l|}
\hline Ano & Total de & $\mathrm{N}^{\circ}$ de & $\mathrm{N}^{\circ}$ de & \% de & $\%$ de & \% eleitas com \\
\hline
\end{tabular}

\footnotetext{
7 - Em 1994 não existia previsão legal para exigência de percentual de candidatas do sexo feminino;

8 - Em 1998 foi a primeira eleição pós lei de cotas de gênero, aumentaram o número de candidatas e diminuiu o numero de eleitas;
} 


\begin{tabular}{|c|c|c|c|c|c|c|}
\hline & eleitos & candidatas & $\begin{array}{c}\text { mulheres } \\
\text { eleitas }\end{array}$ & $\begin{array}{c}\text { mulheres } \\
\text { eleitas }\end{array}$ & $\begin{array}{c}\text { homens } \\
\text { eleitos }\end{array}$ & $\begin{array}{c}\text { relação } N^{\circ} \text { de } \\
\text { candidatas }\end{array}$ \\
\hline 1994 & 513 & 185 & 38 & $7,4 \%$ & $92,6 \%$ & $20,54 \%$ \\
\hline 1998 & 513 & 353 & 29 & $5,6 \%$ & $94,4 \%$ & $8,21 \%$ \\
\hline 2002 & 513 & 490 & 42 & $8,18 \%$ & $91,72 \%$ & $8,57 \%$ \\
\hline 2006 & 513 & 737 & 45 & $8,8 \%$ & $91,2 \%$ & $7,14 \%$ \\
\hline 2010 & 513 & 2.201 & 42 & $8,18 \%$ & $91,72 \%$ & $1,90 \%$ \\
\hline
\end{tabular}

(fonte: TSE) $)^{9}$

\section{Os Pontos Positivos Lei n. 9.504/97 e sua Ineficácia}

A partir desses dados levantados em pesquisa junto ao TSE, pode-se concluir que não teve eficácia a Lei n. 9.504, de 30 de setembro de 1997, que objetivava aumentar o número de cadeiras ocupadas por mulheres junto ao Poder Legislativo no âmbito federal, estadual e municipal.

Observa-se a modalidade escolhida pelos parlamentares brasileiros na criação da política de cotas objetivando a reserva de $30 \%$ na lista eleitoral.

\footnotetext{
9 - Essa tabela foi elaborada com base nos dados retirados do Site do TSE- Tribunal Superior Eleitoral durante o mês de março de 2011(www.tse.gov.br/internet/eleiçoes/ano/cargo_sexo_blank.htm)
} 
para as mulheres. Ainda, somado com todos os fatores históricos culturais, sociais, econômicos e estruturais analisados até aqui, mais a opinião da grande maioria das pesquisadoras, citadas neste texto, que tal modalidade das cotas, também, é responsáveis pela "ineficácia" da lei.

Ratifica-se a existência de duas modalidades de contas adotadas via legislação, aquela que incidem diretamente sobre o parlamento, através da reserva de assentos a serem ocupadas pelas mulheres e as que se aplicam às eleições, isto é, incidem sobre a lista eleitoral, que os partidos irão apresentar. (ARAUJO, 2001, p.03) ${ }^{10}$ que é o caso do Brasil.

Percebe-se que a implantação da cota trouxe para a agenda nacional um grande debate, acerca da pouca presença feminina nos espaços públicos mesmo sendo $51 \%$ da população, elas não conseguiram ainda uma participação significativa na Câmara Federal.

Porém, é notório o aumento de mulheres nos espaços públicos de poder, nos cargos de livre nomeação, podendo citar hoje (10) dez Ministras de Estado, que assessora diretamente a primeira mulher Presidenta da Republica Senhora Dilma Rousseff ${ }^{11}$ eleita no processo eleitoral de 2010.

Assim, entende-se que a partir de 2003 com a criação da Secretaria Especial de Políticas para as Mulheres (SPM) ${ }^{12}$ ampliaram-se os investimentos

10 - Clara Araújo (Potencialidades e limites da Política de Cotas no Brasil) - site www.scielo.br/ref/v9n1/8613.pdf às 10:10 no dia 17 de abril de 2011.

${ }^{11}$ - Primeira mulher a se tornar Presidente da República do Brasil, Dilma Vana Rousseff nasceu em 14 de dezembro de 1947, na cidade de Belo Horizonte (MG). É filha do imigrante búlgaro Pedro Rousseff e da professora Dilma Jane da Silva, nascida em Resende (RJ).

12 - SPM- A Secretaria foi criada através da Medida Provisória 103 , no primeiro dia do governo do presidente Luiz Inácio Lula da Silva, para desenvolver ações conjuntas com todos os Ministérios e Secretarias Especiais, tendo como desafio a incorporação das especificidades das mulheres nas políticas públicas e o estabelecimento das condições necessárias para a sua plena cidadania. 
nas políticas públicas voltadas a inclusão feminina, em âmbito federal, estadual ou municipal.

Contudo, pode-se compreender que apesar dessas políticas objetivarem a eficácia da proposta inicial da Lei n. 9.504/97, seria necessário uma mudança na modalidade da cota. Passando da reserva na lista, para a reserva de cadeiras no parlamento, pois o maior ganho com o modelo atual está no aumento de mulheres na disputa, mas não efetivamente nos assentos dos parlamentos conforme a análise da tabela 9 (Evolução do número de candidatas e de mulheres eleitas para a Câmara Federal no período précota e pós-cota (1994 à 2010)

Tal tabela confirma a presença majoritária dos homens nas cadeiras da Câmara Federal, chegando em 2010 com 91,72\% das vagas ocupadas pelo sexo masculino.

\section{Considerações Finais}

As análises em relação aos fatores que dificultam o acesso das mulheres ao poder no Brasil despertam para o fato de que só a modificação da lei eleitoral não garante o aumento do número de mulheres nos espaços de poder, em razão de existir a necessidade de mudança no comportamento social o qual, ainda, perdura os resquícios de machismo e patriarcalismo.

Tais afirmações são ratificadas pelos dados apresentados neste estudo e pelas críticas da pesquisadora Pinheiro (2007, p. 77). Destacou-se, ainda, a questão da existência das duas modalidades, ditadas pela autora Araújo (2001,p.03), referente a contas adotadas via legislação, aquela que incidem diretamente sobre o parlamento, através da reserva de assentos a serem ocupadas pelas mulheres e as que se aplicam às eleições, isto é, incidem sobre a lista eleitoral, que os partidos irão apresentar. 
Viu-se, ao longo desta exposição, que a implantação da cota foi um imperativo para ocorrer a agenda nacional de debates acerca da pouca presença feminina nos espaços públicos. Mesmo sendo $51 \%$ da população, elas não conseguiram uma participação significativa na Câmara Federal.

Da análise efetuada observou-se, também, o aumento de mulheres nos espaços públicos de poder, nos cargos de livre nomeação dez Ministras de Estado, que assessora diretamente a primeira mulher Presidenta da Republica Senhora Dilma Rousseff ${ }^{13}$ eleita no processo eleitoral de 2010.

Observou-se a ampliação dos investimentos nas políticas públicas voltadas à inclusão feminina, em âmbito federal, estadual ou municipal, em 2003, com a criação da SPM- Secretaria Especial de Políticas para as mulheres.

Contudo, pôde-se compreender que apesar dessas políticas é uma mudança na modalidade da cota. Passando da reserva na lista, para a reserva de cadeiras no parlamento, em razão de o modelo atual está voltado no aumento de mulheres na disputa, mas não efetivamente nos assentos dos parlamentos conforme a análise da tabela 9 (Evolução do número de candidatas e de mulheres eleitas para a Câmara Federal no período précota e pós-cota (1994 à 2010).

\section{REFERÊNCIAS}

ARAÚJO, C. As cotas por Sexo para a competição legislativa: o caso brasileiro em comparação com experiências internacionais. Rio de Janeiro,

\footnotetext{
13 - Primeira mulher a se tornar Presidente da República do Brasil, Dilma Vana Rousseff nasceu em 14 de dezembro de 1947, na cidade de Belo Horizonte (MG). É filha do imigrante búlgaro Pedro Rousseff e da professora Dilma Jane da Silva, nascida em Resende (RJ).
} 
v.44, n.1, jan/2001. Disponível em: < http://www.scielo.br> Acesso em: 24 mar. 2011.

BENEVIDES, Maria Victoria de Mesquita. 1992. A cidadania ativa. São Paulo, Ática, 1998.

BORBA, A. et al. Mulher e Política: gênero e feminismo no Partido dos Trabalhadores. 1 ed. SP: Fundação Perseu Abramo, 1998.

CABRAL, Karina Melissa. Direito da Mulher de acordo com o Novo Código Civil. Editora de Direito, 2004.

CFEMEA. Os direitos das mulheres na legislação brasileira pósconstituinte - Legislação (Federal, Estadual e Municipal) sobre direitos das mulheres a partir da constituição de 1988. Brasília: Letras Livres, 2006.

DELGADO. Maria Berenice Godinho. Mulher e Política: Gênero e feminismo no Partido dos Trabalhadores. São Paulo: Editora Fundação Perseu Abramo, 1998.

FERREIRA, M. Mulher e Política: Do voto feminino à Lei das Cotas: a difícil inserção das mulheres nas democracias representativas. Disponível em: <www.espaçoacademico.com.br/036/37cferreira.htm> Acesso em: 24 mar, 2010.

GARCIA, Ivete. Gênero e políticas públicas municipais. 1998. Disponível em Disponível em http//www2.fpa.org.br/uploads/lvete.pdef. Acesso em 10 de dezembro de 2012.

GODINHO, Tatau. BORBA, Angela (org.) Mulher e Política: Gênero e feminismo no Partido dos Trabalhadores. São Paulo: Editora Fundação Perseu Abramo, 1998. Disponível em http//www2.fpa.org.br/uploads/lvete.pdef. Acesso em 10 de dezembro de 2012.

http://www2.fpa.org.br/uploads/ivete.pdf .. Lei n. 9.100 de 29 de setembro de 1995. Estabelece normas para a realização das eleições municipais de 3 de outubro de 1996, e dá outras providências. Disponível em: <www.planalto.gov.br> Acesso em 28/03/2011. 
. Le n. 9.504 de 30 de setembro de 1997. Estabelece normas para as eleições. Disponível em: <www.planalto.gov.br> Acesso em 28/03/2011

MATOS, Marlise, et al. Cotas de Gênero para o reconhecimento das Mulheres na Política: um estudo comparado ações afirmativas no Brasil, Argentina e Peru. Disponível em: <www.maismulheresnopoderbrasil.com.br> Acesso em: 25 mar. 2011.

MELO, Hildete Pereira. Gênero e Pobreza no Brasil. Relatório Final do Projeto Gonernabilidad Democratica de El Género Em America Latina y El Caribe. Convênio:Comissão Econômica para América Latina e Caribe (CEPAL) Secretaria Especial de Políticas para as Mulheres (SPM),Brasília, 2005.

PAULILO, Maria Ignez Silveira. Mulher e Cidadania. 1999. Disponível em: http://www.ssrevista.uel.br/c v2n2 mulher.htm. Acesso em 17 de mar.2012.

PINHEIRO, Luana Simões. Vozes Femininas na Política: uma análise sobre mulheres parlamentares no pós-Constituinte. Brasília: Secretaria Especial de Políticas para as Mulheres, 2007.

PINTO, Célia Regina Jardim. Uma história do feminismo no Brasil. São Paulo: Fundação Perseu Abramo, 2003.

RAGO, Margareth. A mulher brasileira nos espaços público e privado. São Paulo: Fundação Perseu Abramo, 2004.

RIBEIRO, Matilde. Antigas personagens, novas cenas:mulheres negras e participação política. Disponível em http://empreende.org.br/pdf/Programas\%20e\%20Pol\%C3\%ADticas\%20Sociais/ Antigas\%20personagens\%20mulheres\%20negras.pdf

SOARES, Vera. O feminismo e o machismo na percepção das mulheres brasileiras. In: A mulher brasileira nos espaços público e privado. $1^{\circ}$ ed. São Paulo: Editora Fundação Perseu Abramo, 2004, p. 161-180. 
